\title{
Perfluorochemical (PFC) Combinations for Acute Lung Injury: An In Vitro and In Vivo Study in Juvenile Rabbits
}

\author{
MEI-JY JENG, SHYH-SHENG YANG, MARLA R. WOLFSON, AND THOMAS H. SHAFFER \\ Institute of Clinical Medicine, National Yang-Ming University School of Medicine, and Department of \\ Pediatrics, Children's Medical Center, Veterans General Hospital-Taipei, Taipei 112, Taiwan [M.J.J]; \\ Department of Surgery, Taichung Veterans General Hospital, Taichung 407, Taiwan [S.S.Y.]; \\ Departments of Physiology and Pediatrics, Temple University School of Medicine, Philadelphia, \\ Pennsylvania 19140, U.S.A. [M.J.J., M.R.W, T.H.S]; and Nemours Lung Center, A. I. duPont Hospital for \\ Children, Wilmington, Delaware 19803, U.S.A. [T.H.S]
}

\begin{abstract}
Perfluorochemical (PFC) fluids of different physical properties were titrated and tested in vitro for physical properties that are appropriate for respiratory application. Two PFC liquids were studied: perfluoromethylcyclohexane (PP2), a liquid with high vapor pressure and low viscosity, and perfluoromethyldecalin (PP9), a fluid with low vapor pressure and high viscosity. Eighteen rabbits $(2.05 \pm 0.07 \mathrm{~kg}$; mean \pm SEM $)$ were lunglavaged and randomized: group I, control group; group II, partial liquid ventilation with $75 \%$ PP2 and 25\% PP9; group III, partial liquid ventilation with $50 \%$ PP2 and 50\% PP9; and group IV, partial liquid ventilation with $25 \%$ PP2 and $75 \%$ PP9. Ventilator volumes were kept constant during the 4-h experiment. Cardiopulmonary measurements were performed every $30 \mathrm{~min}$. The lung histology was examined. The in vitro study showed PFC [viscosity/vapor pressure (in $\mathrm{cS}$ and $\mathrm{mm} \mathrm{Hg}$, respectively)] as follows: 100\% PP2 (0.88/141); 100\% PP9 (3.32/2.9); 75\% PP2 and $25 \%$ PP9 (1.26/107); 50\% PP2 and 50\% PP9 (1.63/13.7); and $25 \%$ PP2 and $75 \%$ PP9 (2.21/4.4). The in vivo experiments found that combinations of moderate vapor pressure (groups 3 and 4) demonstrated good gas exchange, compliance, and histo-
\end{abstract}

\section{ABSTRACT}

logic findings. Thus, combinations of PFC liquids can be formulated to modulate the physiologic outcome in acutely injured lungs, and may prove useful for alternative PFC liquid applications. (Pediatr Res 53: 81-88, 2003)

$\quad$ Abbreviations
ALI, acute lung injury
IMV, intermittent mechanical ventilation
OI, oxygenation index
PEEP, positive end-expiratory pressure
PFC, perfluorochemical
PIP, peak inspiratory pressure
PLV, partial liquid ventilation
PP2, perfluoromethylcyclohexane
PP9, perfluoromethyldecalin
C $_{\mathbf{R}}$, respiratory compliance
T50, time needed to evaporate $50 \%$ liquid
TLV, tidal liquid ventilation
VEI, ventilation efficient index

The use of PFC as a medical material has been investigated during the past decades $(1,2)$. Liquid-assisted ventilation, filling the lungs with PFC liquids during mechanical ventilation, including TLV and PLV, has proven effective in treating acute respiratory failure of premature, neonatal, and adult lungs

Received November 2, 2001; accepted May 15, 2002.

Correspondence: Mei-Jy Jeng, M.D., Department of Pediatrics, Children's Medical Center, Veterans General Hospital-Taipei, No. 210, Section 2, Shih-Pai Road, Taipei 112, Taiwan, ROC; e-mail: mjjeng@vghtpe.gov.tw or tshaffer@nemours.org or tshaffer@astro.temple.edu

Supported in part by a grant from the National Heart, Lung, and Blood Institute HL64158.

Presented at the annual meeting of the Pediatric Academic Society and the Society for Pediatric Research, Baltimore, MD, U.S.A., 2001.

DOI: 10.1203/01.PDR.0000041520.50792.0A
(1-11). The properties of different PFC liquids influence physiologic and cellular responses during PLV and affect the dosing strategy $(1,2)$; however, there are a limited number of PFC fluids appropriate for respiratory applications. Although several PFC liquids have been reported for liquid-assisted ventilation, including TLV and PLV (10, 12-18), there have been no studies exploring the effects of combining different PFC liquids to produce a fluid with optimum physical properties for respiratory therapy.

All PFC liquids are immiscible to water, but they are soluble in each other (1). A PFC liquid suitable for respiratory application has the properties of high gas solubility and moderate vapor pressure and viscosity (2). Inasmuch as only a few PFC liquids are good candidates as a respiratory medium, a mixture 
of PFC liquids with different physiochemical properties may result in a better fluid for respiratory applications. PP2 (perfluoromethylcyclohexane; F2 Chemicals; Preston, U.K.) is a PFC liquid with a high vapor pressure $\left(141.0 \mathrm{~mm} \mathrm{Hg}\right.$ at $\left.25^{\circ} \mathrm{C}\right)$ and low viscosity $(0.88 \mathrm{cS})$. In pure form, PP2 would evaporate very fast and need frequent replacement to maintain its physiologic effect, making it impractical for clinical application. On the other hand, PP9 (perfluoromethyldecalin; F2 Chemicals) has a low vapor pressure $\left(2.9 \mathrm{~mm} \mathrm{Hg}\right.$ at $\left.25^{\circ} \mathrm{C}\right)$ and very high viscosity $(3.32 \mathrm{cS})$. The fluid would not evaporate rapidly; however, the high viscosity of PP9 would influence the spreading of PFC liquid and increase the work of breathing (19). We believed it would be difficult to use any one of these fluids alone to maintain effective physiologic responses during the treatment of ALI. Theoretically, a combination of PP2 and PP9 in an appropriate proportion could make a stable PFC liquid with a moderate viscosity and vapor pressure that may be beneficial for PLV in treating injured lungs.

We hypothesized that an appropriate mixture of PP2 and PP9 could result in a PFC liquid that could provide effective physiologic responses during PLV in ALI. The purpose of this study was to titrate PFC fluids of different physical properties to formulate a new fluid with physicochemical characteristics appropriate for respiratory applications, and to test their efficacy for neonatal PLV using a juvenile rabbit lung injury model.

\section{METHODS}

All animals were managed according to the National Institutes of Health regulations "Guide for the Care and Use of Laboratory Animals." In addition, all procedures were approved by the Institutional Animal Care Use Committee of Temple University.

\section{In Vitro Studies}

In our previous studies, we found that a PFC liquid with high vapor pressure, such as FC-77 (vapor pressure, $85 \mathrm{~mm} \mathrm{Hg}$ at $37^{\circ} \mathrm{C}$ and $42 \mathrm{~mm} \mathrm{Hg}$ at $25^{\circ} \mathrm{C}$ ) would need more frequent replacement (approximately $10 \mathrm{~mL} \cdot \mathrm{kg}^{-1} \cdot \mathrm{h}^{-1}$ ) than perflubron $\left(1-5 \mathrm{~mL} \cdot \mathrm{kg}^{-1} \cdot \mathrm{h}^{-1}\right)$, which is commonly used in animal studies and clinical trials $(10,11,20,21)$. In addition, in other studies we found that a PFC liquid with high viscosity, such as perfluorodecalin (viscosity, $2.61 \mathrm{cS}$ ), could not maintain oxygenation in clinically acceptable levels compared with studies with perflubron for $4 \mathrm{~h}(12,20)$. The vapor pressure of PP2 $\left(141 \mathrm{~mm} \mathrm{Hg}\right.$ at $\left.25^{\circ} \mathrm{C}\right)$ is higher than that of FC-77, and the viscosity of PP9 (3.32 cS) is higher than that of perfluorodecalin. Therefore, we chose to use the mixture of PP2 and PP9 to perform our PLV study. Thus, three combinations of PP2 and PP9 liquids were made and investigated: $75 \%$ PP2 and $25 \%$ PP9, 50\% PP2 and 50\% PP9, and 25\% PP2 and $75 \%$ PP9. To determine the physical properties of these mixtures, we performed in vitro testing against PFC liquid standards with known physical properties [PP2 (C7F14), PP4 (perfluoro-1, 3, 5-trimethyl-cyclohexane, C9F18), PP9 (C11F20); all F2 Chemicals; APF-125 (perfluorodimethyl-cyclohexane, C9F18), APF-140 (perfluorodecalin, C10 F8); Air Products,
Allentown, PA, U.S.A.; and perflubron (C8F17Br); LiquiVent; Alliance In Pharmaceutical Corp., San Diego, CA, U.S.A.]. Each in vitro test was repeated three times, and the mean values of each test were analyzed and correlated with the PFC standards.

Density test. The immediate weight of each 1-mL sample (mixture and standard) was recorded with a balance (Explorer, Ohaus; Pine Brook, NJ, U.S.A.; resolution to $10^{-4} \mathrm{~g}$ ) before evaporative loss. The density (milligrams per milliliter) of the PFC mixtures was based on the average of three repeated measurements.

Vapor pressure test. Each 1-mL sample (mixture and standard) was placed on a balance (Explorer, Ohaus; resolution to $10^{-4} \mathrm{~g}$ ) with the top lid opened and constant room temperature $\left(24-25^{\circ} \mathrm{C}\right)$. This procedure is a standard test for analyzing PFC evaporation rate (personal communication, Dr. Frank Schweighardt, Air Products, Allentown, PA, U.S.A.). The weight change of each sample was recorded every $5 \mathrm{~min}$ for the first $60 \mathrm{~min}$, and then every $10 \mathrm{~min}$ up to $4 \mathrm{~h}$ unless evaporation was completed earlier. The time needed to evaporate $50 \%$ of the initial $1 \mathrm{~mL}$ of PFC (T50) was recorded and correlated with T50 for PFC liquids with known vapor pressures (PP2, PP4, APF-140, PP9, APF-125, and perflubron) to establish a linear regression equation. The vapor pressure of the mixtures was then calculated from the regression equation.

Viscosity test. We instilled $0.2 \mathrm{~mL}$ of each sample (mixture and standard) into a thin-walled polyvinyl chloride tube (internal diameter, $0.15 \mathrm{~cm}$ ), and the time needed to pass $75 \mathrm{~cm}$ vertically down through the catheter was recorded as catheter transient time. This measurement procedure was adapted from the chemical industry (personal communication, Dr. DirkHenning Menz, Pharmpur, Augsburg, Germany). The correlation of known PFC fluid viscosities (PP2, PP4, APF-140, PP9, APF-125, and perflubron) and the catheter transient time was analyzed; a regression equation was determined. As above, the viscosity of the mixtures was calculated by the regression equation.

\section{In Vivo Studies}

Animal preparation. Twenty New Zealand White juvenile rabbits (8-10 wk old; weight, $1.5-2.5 \mathrm{~kg})$ were anesthetized with an intramuscular injection of a mixture of ketamine (23 $\mathrm{mg} / \mathrm{kg})$, acepromazine $(0.58 \mathrm{mg} / \mathrm{kg})$, and xylazine $(0.8 \mathrm{mg} / \mathrm{kg})$. This particular animal model was chosen based on our previous experience with the model, the suitability of the model as it applies to neonatal and pediatric medicine, and the history of this preparation for PLV studies $(12,22-25)$. The skin and soft tissues were anesthetized with $0.5 \%$ lidocaine $\mathrm{HCl}(4 \mathrm{mg} / \mathrm{kg})$, and the animals were instrumented with tracheostomy placement of a 3-mm-internal diameter endotracheal tube (Hi-Lo Jet Tube: Mallinckrodt, St. Louis, MO, U.S.A.). Catheters were placed in the jugular vein and carotid artery. Subsequent anesthesia was maintained with an i.v. injection of sodium pentobarbital $5 \mathrm{mg} / \mathrm{kg}$ as needed or hourly. Muscle relaxation was induced by i.v. administration of pancuronium bromide $(0.1 \mathrm{mg} / \mathrm{kg})$ and maintained with continuous infusion $(0.15$ $\left.\mathrm{mg} \cdot \mathrm{kg}^{-1} \cdot \mathrm{h}^{-1}\right)$ throughout the experiments. Maintenance fluid 
was provided by a continuous infusion of $5 \%$ dextrose at a rate of $5 \mathrm{~mL} \cdot \mathrm{kg}^{-1} \cdot \mathrm{h}^{-1}$. Arterial blood pressure was monitored by attaching the arterial catheter to a standard pressure transducer connected to a neonatal monitor (Athena/Neonatal 9040; S \& W Medico Teknik, Albertslund, Denmark). ECG electrodes and a rectal temperature probe were inserted for monitoring. The animal's rectal temperature was maintained within $37-38^{\circ} \mathrm{C}$

$\mathrm{C}_{\mathrm{R}}$ was measured as previously described using the least mean squares technique (Peds MAS, Hatfield, PA, U.S.A.) incorporating pneumotachography and airway manometry (12, 26). Arterial blood gases (Stat profile, Nova Biomedical, Waltham, MA, U.S.A.) were also measured in all groups.

IMV with a time-cycled, pressure-limited ventilator (BP200, Bear Medical Systems, Inc., Riverside, CA, U.S.A.) was established to maintain physiologic cardiopulmonary conditions. The IMV settings were at an inspired oxygen fraction of 1.0 , a frequency of 30 breaths $/ \mathrm{min}$, an inspiratory time of $0.3 \mathrm{~s}$, and a PEEP of $0.4 \mathrm{kPa}\left(4 \mathrm{~cm} \mathrm{H}_{2} \mathrm{O}\right)$. PIP was the only ventilator variable manipulated during the study protocol. We adjusted the PIP to maintain a constant tidal volume of approximately 9 $\mathrm{mL} / \mathrm{kg}$ while limiting the maximal PIP to $3 \mathrm{kPa}\left(30 \mathrm{~cm} \mathrm{H}_{2} \mathrm{O}\right)$ (12).

Protocol. After obtaining the baseline measurements in all animals on IMV, we induced a lung injury by repeatedly lavaging the lungs with $10 \mathrm{~mL} / \mathrm{kg}$ of warm normal saline solution until injury entry criteria were achieved: arterial $\mathrm{Po}_{2}<100 \mathrm{~mm} \mathrm{Hg}$ [13.3 $\mathrm{kPa}$ ] with a more than $50 \%$ decrease in $\mathrm{C}_{\mathrm{R}}$ maintained for more than $20 \mathrm{~min}$ (12). Then, the animals were randomly assigned to one of four groups: group I (control group), treated with IMV only; group II, treated with PLV (75\% PP2 and 25\% PP9); group III, treated with PLV (50\% PP2 and 50\% PP9); and group IV, treated with PLV (25\% PP2 and 75\% PP9). For the PLV groups, the $18 \mathrm{~mL} / \mathrm{kg}$ PFC $(1,20,27)$ was instilled into the lungs of PLV-treated animals via the side port of the endotracheal tube for 5-10 min. During instillation, the animals were repositioned to optimize PFC distribution using four equal increments of the total dose with Trendelenburg, reverse Trendelenburg, and left and right lateral decubitus positions. After instillation, the animals' position (supine), airway temperature $\left(35^{\circ} \mathrm{C}\right)$, and humidity $(100 \%)$ were kept constant throughout the experiment. No PFC replacement was designed in this $4-\mathrm{h}$ experiment. The arterial blood gases, $C_{R}$, and physiologic data were measured and recorded again after lung injury and then every $30 \mathrm{~min}$ for $4 \mathrm{~h}$ or until death.

The OI and VEI were computed as previously described (12, 28, 29): OI $=[($ mean airway pressure $\times$ inspired oxygen fraction) $\left./ \mathrm{Po}_{2}(\mathrm{~mm} \mathrm{Hg})\right] \times 100 ; \mathrm{VEI}=3800 /$ [respiratory rate $\left.(\mathrm{PIP}-\mathrm{PEEP}) \times \mathrm{PCO}_{2}(\mathrm{~mm} \mathrm{Hg})\right]$, where VEI relates alveolar ventilation to respirator input, and 3800 is a constant for estimating alveolar ventilation $\left(3800 / \mathrm{PCO}_{2}\right)$ with the assumption of $\mathrm{CO}_{2}$ production near normal minimal volumes of 5 $\mathrm{mL} \cdot \mathrm{kg}^{-1} \cdot \mathrm{min}^{-1}$ in resting animals.

Lung histology. At the end of the experiments the animals were euthanized with a high dose of $15 \%$ potassium chloride. The chests were opened, and the lungs and thoraces were inspected to assess gross morphology. Within 5 min of death, the ventilator was stopped and continuous positive airway pressure equivalent to the final PEEP was applied. Samples within the dependent and nondependent regions of the lungs were obtained. The lung samples ( $0.5-$ to $1.0-\mathrm{cm}^{3}$ blocks) were immediately placed in $10 \%$ formalin. Routine techniques were used to prepare the lung tissues for paraffin embedding (30). Thin sections were stained with hematoxylin and eosin stain. The sections were examined by light microscopy.

\section{Statistics}

Linear regression was used to analyze the relationships of vapor pressure to $(1 / \mathrm{T} 50)^{2}$ and of viscosity to related catheter transient time. One-way ANOVA was used to compare basic physiologic data among groups. A paired $t$ test was used to compare pre- and postinjured data within groups. Two-way repeated measures ANOVA was used to compare data of gas exchange, OI, VEI, $\mathrm{C}_{\mathrm{R}}$, heart rate, and blood pressure, as a function of time and group. Post hoc testing with the StudentNewman-Keuls' test was used to determined significance. Significance was accepted at the $p<0.05$ level. Values are presented as mean \pm SEM.

\section{RESULTS}

In vitro data. Figures 1 and 2 demonstrate a linear relationship between vapor pressure and (1/T50) and between viscosity and catheter transient time for the six PFC liquids with known properties. The vapor pressure and viscosity of the new PFC combinations were calculated by the regression equations for Figures 1 and 2, and are shown in Table 1. The molecular weight, density, viscosity, and vapor pressure of the new PFC combinations, as may be expected, fell between the data for pure PP2 and PP9.

In vivo data. Two animals died during the saline-lavage phase before randomization and consequently were excluded from further data analysis. As shown in Table 2, body weights $(2.05 \pm 0.07 \mathrm{~kg}$, totally) and the numbers of saline lavages did not differ significantly among groups. Saline lavages resulted in a similar pattern of lung injury in all studied groups. The values of postinjury OI (increased to $10.7 \pm 0.6$ times of preinjury levels), VEI (decreased to $28.8 \pm 1.7 \%$ of preinjury levels), and $C_{R}$ (decreased to $41.5 \pm 2.1 \%$ of preinjury levels)

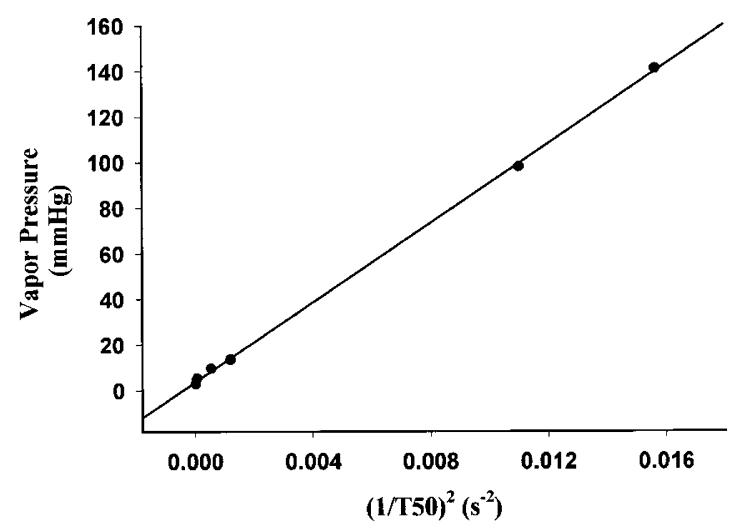

Figure 1. Linear relationship between vapor pressure and $(1 / \mathrm{T} 50)^{2}$ of perfluorochemicals. Regression equation: $y=3.70+8715.56 x, r^{2}=0.999, p<$ 0.001 . 


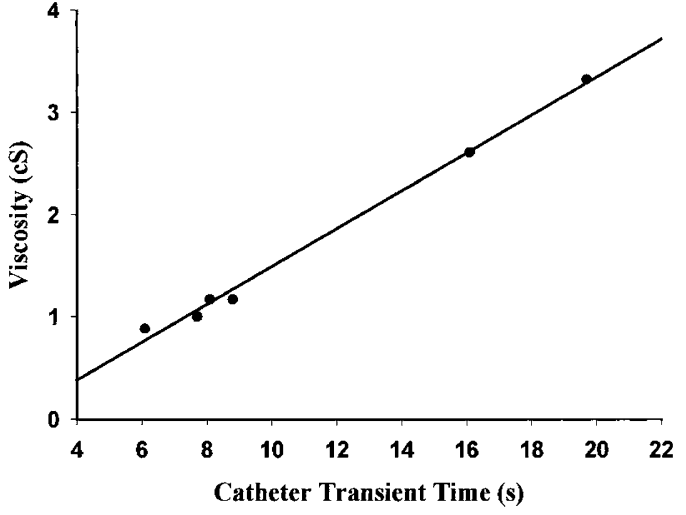

Figure 2. Linear relationship between viscosity and the catheter transient time of perfluorochemicals. Regression equation: $y=-0.36+0.19 x ; r^{2}=$ $0.995, p<0.01$.

Table 1. Known and calculated* properties of different perfluorochemicals at $25^{\circ} \mathrm{C}$

\begin{tabular}{lcccc}
\hline Perfluorochemicals & $\begin{array}{c}\text { Molecular weight } \\
(\mathrm{g} / \mathrm{mol})\end{array}$ & $\begin{array}{c}\text { Density } \\
(\mathrm{g} / \mathrm{mL})\end{array}$ & $\begin{array}{c}\text { Viscosity } \\
(\mathrm{cS})\end{array}$ & $\begin{array}{c}\text { Vapor pressure } \\
(\mathrm{mmHg})\end{array}$ \\
\hline PP2 (C7F14) & 350 & 1.79 & 0.88 & 141.0 \\
PP4 (C9F18) & 450 & 1.86 & 1.17 & 9.6 \\
APF-140 (C10F8) & 462 & 1.87 & 2.61 & 13.5 \\
PP9 (C11F20) & 512 & 1.97 & 3.32 & 2.9 \\
APF-125 (C9F18) & 450 & 1.86 & 1.17 & 98 \\
Perflubron (C8F17Br) & 499 & 1.89 & 1.00 & 5.2 \\
75\% PP2/25\% PP9* & 391 & 1.83 & 1.26 & 107.6 \\
50\% PP2/50\% PP9* & 431 & 1.88 & 1.63 & 13.7 \\
25\% PP2/75\% PP9* & 472 & 1.89 & 2.21 & 4.4 \\
\hline
\end{tabular}

were significantly $(p<0.05)$ different from their corresponding preinjury values for each group. There was no significant difference in pre- and postinjury data as a function of group.

The arterial blood gas analysis showed significantly higher $\mathrm{PO}_{2}$, lower $\mathrm{PCO}_{2}$, and higher $\mathrm{pH}$ in groups III and IV than groups I and II $(p<0.05)$ during the 4 -h experiment. There was no significant difference between groups I and II, or between groups III and IV. The changes in arterial $\mathrm{PO}_{2}, \mathrm{PCO}_{2}$, and $\mathrm{pH}$ also were significant as a function of time $(p<0.0001$; Fig. 3). With further analysis (Table 3 ), the $\mathrm{OI}$ in groups III and IV was significantly lower $(p<0.05)$ than that in groups I and II. However, there was no significance in the change of VEI among groups with time. Two animals from group I and one animal from group II died before the end of the 4-h postinjury study period as a result of severe lung injury. All animals from groups III and IV survived throughout the 4-h postinjury experiment.

Figure 4 demonstrated the $C_{R}$ changes in experimental animals as a function of time. The $C_{R}$ of group I (control group) progressively deteriorated in $4 \mathrm{~h}$. The average $C_{R}$ in all PLV-treated groups increased approximately 1.5 times the postinjury value by $30 \mathrm{~min}$ after treatment. $C_{R}$ decreased rapidly in group II, whereas, with time, the decrease was progressive in group III and very gradual in group IV. Further analysis with two-way ANOVA (repeated measures) showed that only group IV was significantly better than group I ( $p<$ $0.05)$ with respect to the change of $C_{R}$ with time. In addition, there was a significant change in $C_{R}(p<0.0001)$ with time for all groups.

The mean arterial pressure remained stable in groups III and IV; however, that of groups I and II decreased progressively ( $p$ $<0.0001)$ with time. Furthermore, there was a significant difference between groups III/IV and I/II $(p<0.05$; Fig. 5, top). When comparing the change in heart rate with time, there was a small but significant $(p<0.01)$ decline over the 4-h study, but there was no significant difference among groups (Fig. 5, bottom).

The representative photomicrographs of histologic findings are shown in Figure 6. On the dependent sites, marked alveolar structural damage with severe inflammation, hemorrhage, atelectasis, and exudate formation were noted in groups I and II; this damage was markedly decreased in groups III and IV. Similar damage could also be seen in the nondependent sites of groups I, II, and III; however, this was less severe in group IV.

\section{DISCUSSION}

The presented results demonstrate a method for combining PFC fluids to modify their physical properties and an in vitro method to estimate the density, viscosity, and vapor pressure of PFC liquid combinations. The in vivo data support the hypothesis that PFC liquids can be combined with specific physiochemical properties and that, when used during PLV, they can be effective in treating ALI. In addition, these data show that the physiologic and histologic effects of PLV are dependent on the proportion of different PFC fluids. In this study, for example, using a fluid combination such as $25 \%$ PP2 and $75 \%$ PP9

Table 2. Characteristics of animals pre-and post-injury of lungs (mean $\pm S E$ )

\begin{tabular}{|c|c|c|c|c|}
\hline Group & $\mathrm{I}(\mathrm{n}=5)$ & $\mathrm{II}(\mathrm{n}=5)$ & III $(n=4)$ & IV $(n=4)$ \\
\hline Body weight $(\mathrm{kg})$ & $1.97 \pm 0.10$ & $1.93 \pm 0.15$ & $2.02 \pm 0.17$ & $2.06 \pm 0.20$ \\
\hline Lavages (times) & $6 \pm 1$ & $6 \pm 1$ & $6 \pm 1$ & $6 \pm 1$ \\
\hline \multicolumn{5}{|l|}{ Pre-injury } \\
\hline VEI & $0.43 \pm 0.04$ & $0.44 \pm 0.04$ & $0.50 \pm 0.07$ & $0.48 \pm 0.01$ \\
\hline $\mathrm{C}_{\mathrm{R}}$ & $1.01 \pm 0.10$ & $1.03 \pm 0.10$ & $1.04 \pm 0.10$ & $1.11 \pm 0.10$ \\
\hline \multicolumn{5}{|l|}{ Post-injury } \\
\hline $\mathrm{C}_{\mathrm{R}}$ & $0.42 \pm 0.03 *$ & $0.42 \pm 0.03 *$ & $0.43 \pm 0.05^{*}$ & $0.42 \pm 0.01 *$ \\
\hline
\end{tabular}

Values are mean \pm SEM. OI, oxygenation index; VEI, ventilation efficiency index; $\mathrm{C}_{\mathrm{R}}$, respiratory compliance $\left(\mathrm{mL} / \mathrm{cmH}_{2} \mathrm{O} / \mathrm{kg}\right)$. Gr. I: control group; Gr. II: PLV (75\% PP2/25\% PP9); Gr. III: PLV (50\% PP2/50\% PP9); Gr. IV: PLV (25\% PP2/75\% PP9). * p < 0.05 vs. corresponding data of pre-injury. No significant difference among groups. 


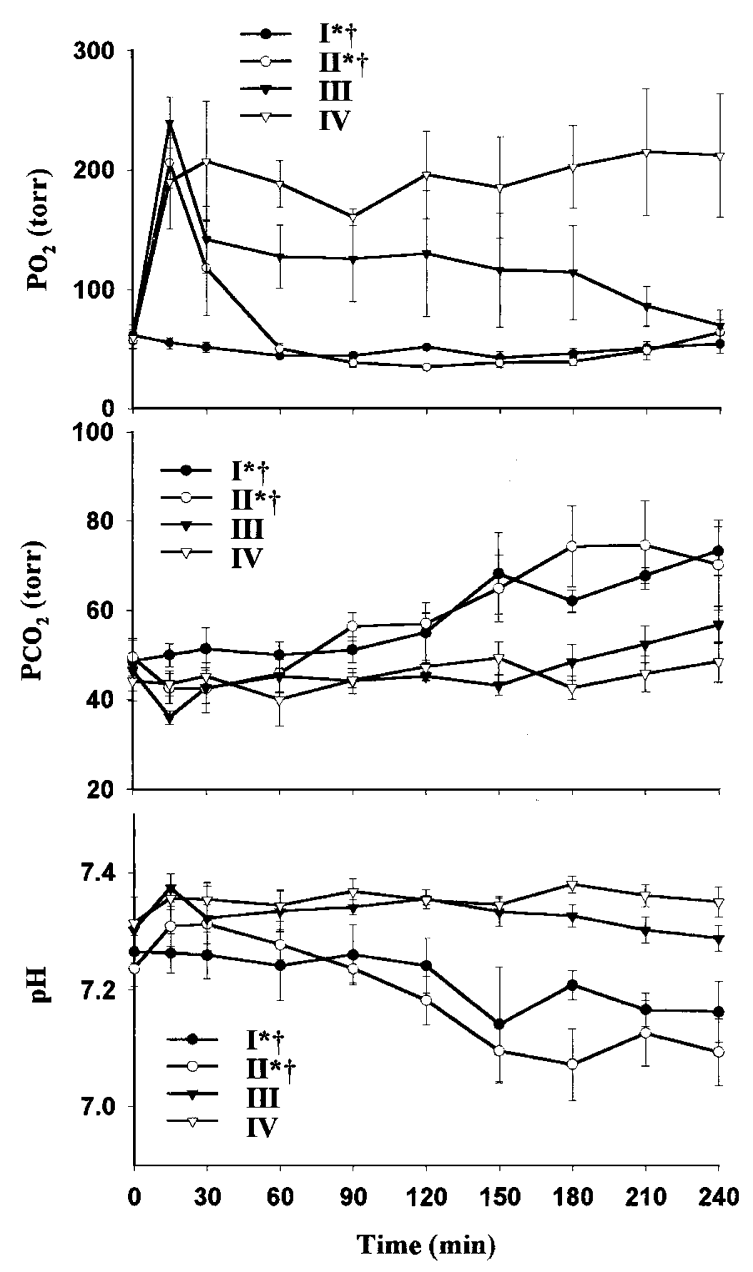

Figure 3. Arterial blood gas measurements in animals treated with different combinations of perfluorochemicals. Values are mean \pm SEM. To convert $\mathrm{mm}$ $\mathrm{Hg}$ to $\mathrm{kPa}$, multiply the value by 0.1333 . Group I, control group $(n=5)$; group II, PLV (75\% PP2 and 25\% PP9, $n=5$ ); group III, PLV (50\% PP2 and 50\% PP9, $n=4)$; group IV, PLV (25\% PP2 and 75\% PP9, $n=4) .{ }^{*} p<0.05 v s$ group III, $\dagger p<0.05$ vs group IV.

(a low proportion of high vapor pressure and high proportion of low vapor pressure) can maintain good gas exchange and lung integrity for a 4-h therapy without fluid replacement.

PFC liquids are essentially biologically inert and it has been shown that they have no deleterious histologic, cellular, or biochemical effects $(1,2,31)$. PFC fluids have been investigated as respiratory media (1-11) for treating ALI, pulmonary administration of drugs $(2,32,33)$, radiologic imaging and diagnosis (34), artificial red blood cell substitution $(2,35,36)$, and vitreous fluid substitution (6) in animal and human studies. All the reported studies have used a single pure PFC liquid. However, the physical properties of the combinational fluid may be better suited for a particular application than either of the pure fluids. Our experiments demonstrated the effective response of two PFC combinations with no complications, although the relative proportions of the PFC liquids, such as a higher proportion of $\mathrm{PP} 9$, could maintain a better gas exchange for $4 \mathrm{~h}$ and determine their physiologic and histologic effects. Therefore, in addition to respiratory support, a PFC fluid combination may be applicable in other medical applications as well, such as drug delivery, lavage, and pulmonary imaging. Further investigation will be necessary to clarify the utility of these other applications.

After more than $30 \mathrm{y}$ of animal studies, the first human trial of TLV was performed in 1989 (5). During the last $10 \mathrm{y}$, the use of PLV to treat premature lungs and other causes of ALI has been reported in experimental and clinical studies $(4,9-11$, $26,27,37)$. Although the effect of PLV has been demonstrated in improving gas exchange, lung mechanics, and alveolar recruitment $(10,12-18)$, some related issues still require clarification. Perflubron has been extensively tested in many animal models and clinical studies, but some investigators have elected to use different PFC liquids, such as Rimar 101 (18), FC-84 (16,17), PF-5080 (14), perfluorodecalin $(12,38)$, and FC-77 $(13,15,21)$. Some investigators also focused on several technical issues, such as dosing and replacement strategies (19, $20,30,38-40$ ), ventilation strategy (22), and the monitoring of the PFC loss amount $(19,23,24,41,42)$. Our results demonstrate the potential effects of a new study focus that includes modification of the PFC liquid physical properties to improve gas exchange, lung mechanics, and histology during PLV. In terms of clinical application, the appropriate fluid for liquidassisted ventilation will depend on the clinical situation. For example, a more viscous fluid may be more appropriate for supporting the lung during extracorporeal membrane oxygenation during which the PFC application is aimed at preventing atelectasis and fluid flux across lung-at-rest conditions. In contrast, a less viscous fluid may be preferred for TLV during which tidal volumes of fluid are exchanged. For PLV, a fluid with low vapor pressure would reduce dosing requirements during the course of the treatment. Thus, the data presented herein further relate fluid physical properties with liquid ventilation applications.

As shown in Table 1, PP2 liquid has a low density, low viscosity, and relatively very high vapor pressure, so it may evaporate in a few minutes after exposure to gas, thus reducing the recruitment aspect of PLV. In contrast, PP9 has high density, very high viscosity, and very low vapor pressure. Although PP9 will not evaporate rapidly, the increased respiratory work caused by viscosity and delayed clearing from the lungs after finishing the therapy may be a serious detriment for using this fluid during PLV. Therefore, neither fluid alone could maintain ideal physiologic conditions for PLV. As shown herein, an appropriate mixture of these fluids (25\% PP2 and $75 \%$ PP9) has the advantage of adjusting vapor pressure of PFC liquid to prolong the redosing intervals and altering viscosity to uniformly distribute, recruit lung volume, and lower surface tension.

On the basis of our physiologic and histologic findings, the effect of PLV with different combinations of PP2 and PP9 was dependent on the proportionality of the mixture. The oxygenation of animals treated with $75 \%$ PP2 and 25\% PP9 was improved relative to control levels in the first $30 \mathrm{~min}$, and the $C_{R}$ was elevated for the first 60 min, after which these physiologic values decreased to levels similar to those of the control group. This response is most likely related to the rapid evaporation of PP2 and the low residual volume of PP9 (only less than one fourth of functional residual capacity amount), which 
Table 3. Oxygenation index (OI), ventilation efficiency index (VEI) and survival rate in animals treated with different combinations of perfluorochemicals

\begin{tabular}{|c|c|c|c|c|c|}
\hline \multirow{3}{*}{ OI } & \multirow[t]{3}{*}{ Time } & \multicolumn{4}{|c|}{ Group } \\
\hline & & $I^{* \dagger}$ & II ${ }^{* \dagger}$ & $\mathrm{III \dagger}$ & IV \\
\hline & & $(n=5)$ & $(n=5)$ & $(n=4)$ & $(n=4)$ \\
\hline & $1 \mathrm{~h}$ & $22.3 \pm 1.1$ & $16.5 \pm 2.5$ & $6.4 \pm 1.2$ & $4.9 \pm 1.2$ \\
\hline & $3 \mathrm{~h}$ & $22.7 \pm 3.6$ & $21.7 \pm 2.2$ & $9.2 \pm 2.1$ & $4.4 \pm 0.8$ \\
\hline & $4 \mathrm{~h}$ & $20.1 \pm 3.7$ & $17.7 \pm 2.4$ & $13.1 \pm 2.6$ & $5.3 \pm 1.4$ \\
\hline VEI & & I & II & III & IV \\
\hline & $3 \mathrm{~h}$ & $0.08 \pm 0.0$ & $0.08 \pm 0.02$ & $0.10 \pm 0.01$ & $0.14 \pm 0.01$ \\
\hline & $4 \mathrm{~h}$ & $0.07 \pm 0.01$ & $0.08 \pm 0.02$ & $0.08 \pm 0.01$ & $0.12 \pm 0.01$ \\
\hline Survival & & $3 / 5(60 \%)$ & $4 / 5(80 \%)$ & $4 / 4(100 \%)$ & $4 / 4(100 \%)$ \\
\hline
\end{tabular}

Values are mean \pm SEM. Gr. I: control group; Gr. II: PLV (75\% PP2/25\% PP9); Gr. III: PLV (50\% PP2/50\% PP9); Gr. IV: PLV (25\% PP2/75\% PP9). * p < 0.05 vs. Gr. III, $\uparrow \mathrm{p}<0.05$ vs. Gr. IV.

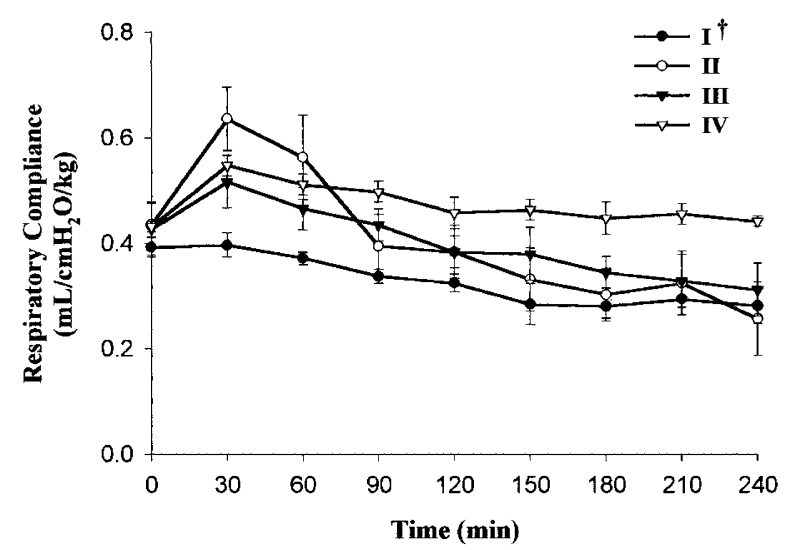

Figure 4. $C_{R}$ in animals treated with different combinations of perfluorochemicals. Values are mean \pm SEM. Group I, control group $(n=5)$; group II, PLV (75\% PP2 and 25\% PP9, $n=5)$; group III, PLV ( $50 \%$ PP2 and 50\% PP9, $n=4)$; group IV, PLV (25\% PP2 and 75\% PP9, $n=4)$. $\dagger p<0.05 v$ group IV.

is not enough to maintain gas exchange in a severely damaged lung. Animals treated with $50 \%$ PP2 and $50 \%$ PP9 or $25 \%$ PP2 and $75 \%$ PP9 demonstrated better gas exchange and stable hemodynamic conditions, and all survived the 4-h experiment. However, during the last hour of the experiment, oxygenation with the $50 \%$ PP2 and 50\% PP9 liquid dropped to a critical level $(<100 \mathrm{~mm} \mathrm{Hg}, 13.3 \mathrm{kPa})$. In addition, it was found that $C_{R}$ could not be maintained for the 4-h study, and lung histopathology showed severe injury in nondependent sites. PFC fluid combinations with a higher portion of PP9 (25\% PP2 and $75 \%$ PP9) most effectively maintained physiologic function and histologic outcome. In combining PP2 and PP9 fluids, the resultant mixture had properties between the values of the original pure liquids. Among the physical properties, the densities of fluid combinations did not differ substantially; however, the viscosity and vapor pressure were very much dependent on the proportionality of the original fluids. The mixture with $75 \%$ PP2 and 25\% PP9 had a high vapor pressure (107.6 $\mathrm{mm} \mathrm{Hg}$ at $25^{\circ} \mathrm{C}$ ) whereas $25 \% \mathrm{PP} 2$ and $75 \%$ PP9 had a low vapor pressure $\left(4.4 \mathrm{~mm} \mathrm{Hg}\right.$ at $\left.25^{\circ} \mathrm{C}\right)$. It is noteworthy that this mixture had a vapor pressure similar to that of perflubron (5.2 $\mathrm{mm} \mathrm{Hg}$ at $25^{\circ} \mathrm{C}$ ), which has been used most extensively for animal and human PLV studies $(3,5,7-11,21,25,26)$.

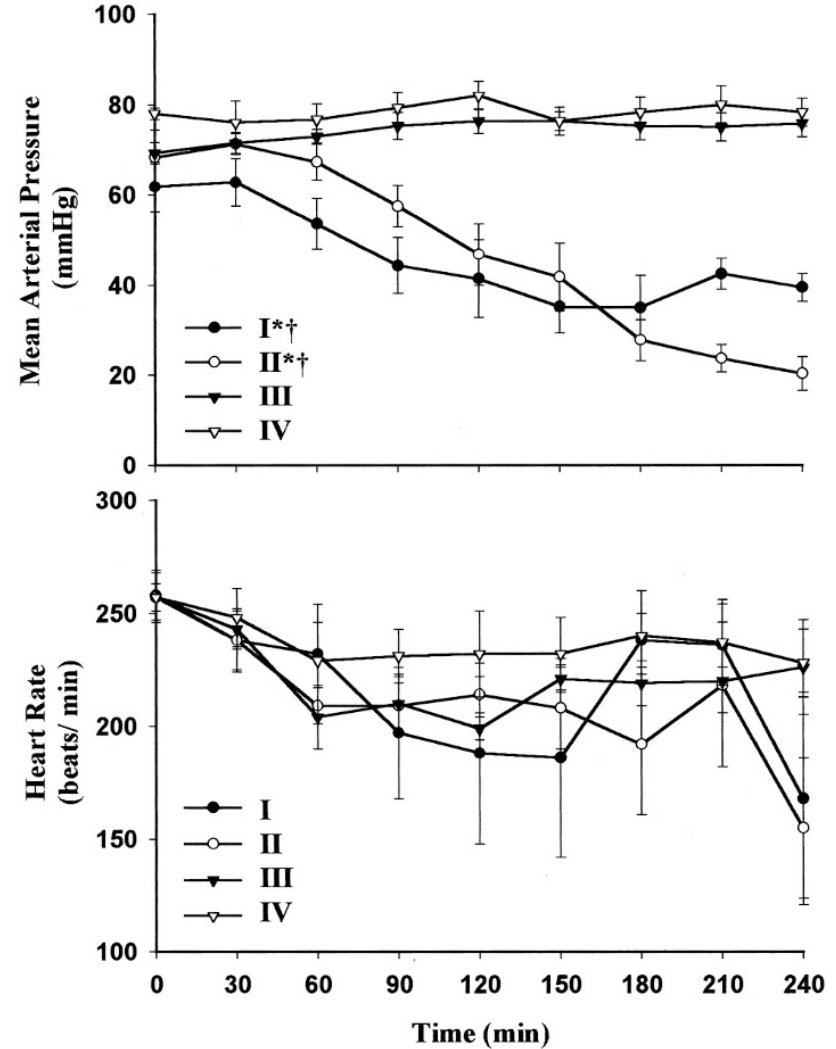

Figure 5. Mean arterial pressure and heart rate in animals treated with different combinations of perfluorochemicals. Values are mean \pm SEM. Group I, control group $(n=5)$; group II, PLV (75\% PP2 and $25 \% \mathrm{PP} 9, n=5)$; group III, PLV (50\% PP2 and 50\% PP9, $n=4)$; group IV, PLV (25\% PP2 and 75\% PP9, $n=4) . * p<0.05$ vs group III, $\dagger p<0.05$ vs group IV.

Furthermore, the viscosity of the mixture with $75 \%$ PP2 and $25 \%$ PP9 $(1.26 \mathrm{cS})$ was similar to that of perflubron $(1.00 \mathrm{cS})$, but the mixture 25\% PP2 and 75\% PP9 $(2.21 \mathrm{cS})$ had a viscosity approximately twice that of perflubron. Therefore, the role of vapor pressure appears to be a more important physical property than viscosity to maintain physiologic and histologic integrity during PLV.

In a recent study we found that when PLV was used to treat ALI with an amount of perflubron equal to functional residual capacity, the response could be maintained for $4 \mathrm{~h}$ and replace- 

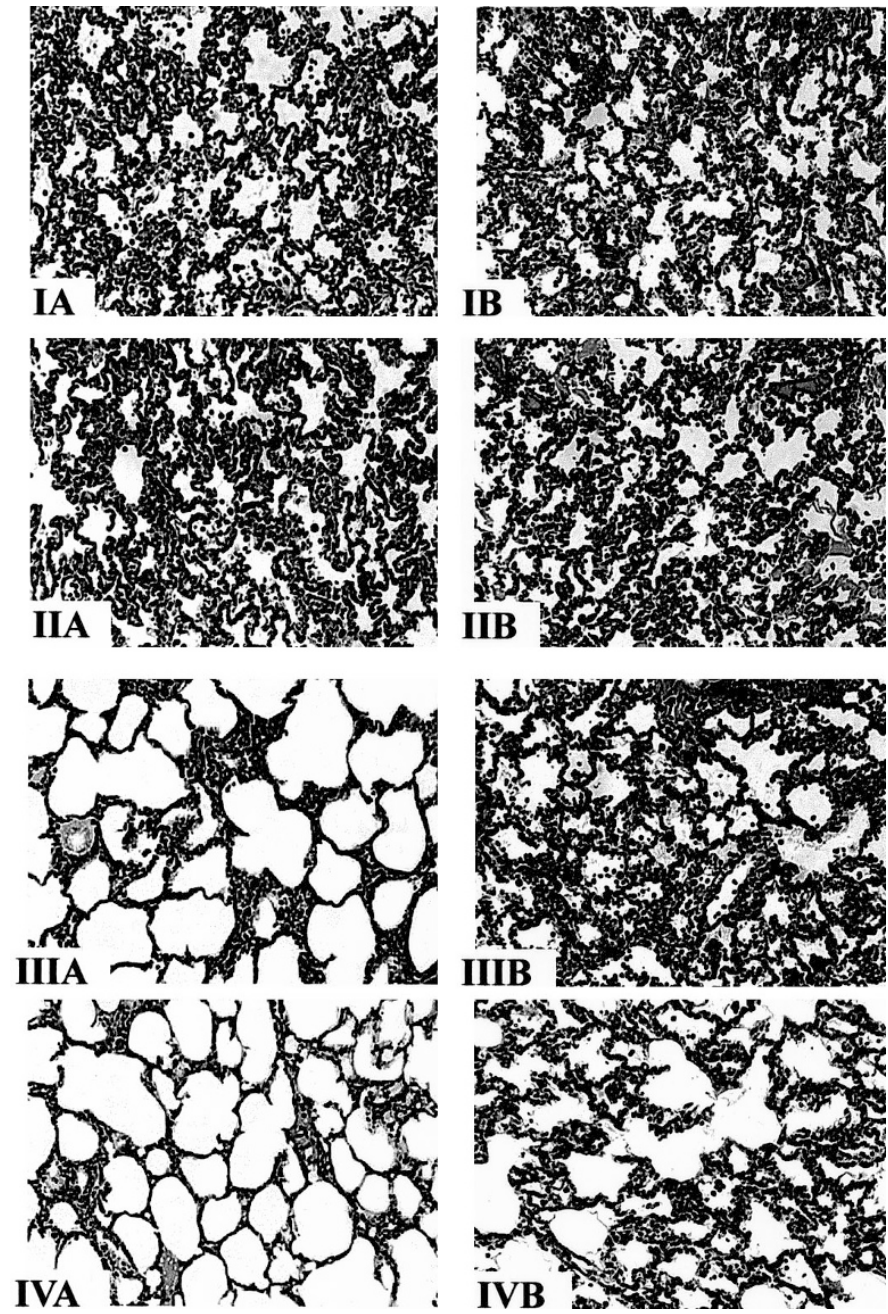

Figure 6. Photomicrographs $(\times 200)$ of lung sections in different groups. $A$, obtained from the dependent sites of each group; $B$, obtained from the nondependent sites of each group. Group I, control group; group II, PLV (75\% PP2 and 25\% PP9); group III, PLV (50\% PP2 and 50\% PP9); group IV, PLV (25\% PP2 and $75 \%$ PP9).

ment dosing had little effect on physiologic and histologic outcome (20), thus showing the clinical implication of less frequent fluid replacement. The animal model, type, and severity of lung injury of these two studies were similar. In addition, the dosing strategy of the animals treated with 18 $\mathrm{mL} / \mathrm{kg}$ of perflubron with no replacement for $4 \mathrm{~h}$ was the same as in the present study (20). If we compare the animals in the perflubron study with the present results, we find that only the animals treated with $25 \%$ PP2 and $75 \%$ PP9 had similar responses in oxygenation, $\mathrm{C}_{\mathrm{R}}$ and lung histology. These findings again demonstrate the importance of vapor pressure in regulating dose maintenance.

\section{CONCLUSION}

We conclude that the PFC fluid combinations with high proportions of PP9 and low proportions of PP2 are effective in supporting gas exchange, $C_{R}$, and lung integrity during PLV in ALI. In the present study, we evaluated only three fluid combinations; further studies are required to optimize a more exact
PFC fluid combination that would maximize physiologic responses while minimizing redosing requirements.

Acknowledgments. The authors gratefully acknowledge the expert technical assistance of Rita Garbarino and Aaron B. Cullen at Temple University and Barbara Gray at the Nemours Lung Center, and the statistical advisement of Benjamin IngTiau Kuo, M.D., Dr.P.H., at National Yang-Ming University.

\section{REFERENCES}

1. Shaffer TH, Wolfson MR, Clark LC 1992 Liquid ventilation. Pediatr Pulmonol 14:102-109

2. Wolfson MR, Greenspan JS, Shaffer TH 1998 Liquid-assisted ventilation: an alternative respiratory modality. Pediatr Pulmonol 26:42-63

3. Fujino Y, Goddon S, Chiche JD, Hromi J, Kacmarek RM 2000 Partial liquid ventilation ventilates better than gas ventilation. Am J Respir Crit Care Med 162:650-657

4. Gauger PG, Pranikoff T, Schreiner RJ, Moler FW, Hirschl RB 1996 Initial experience with partial liquid ventilation in pediatric patients with acute respiratory distress syndrome. Crit Care Med 24:16-22

5. Greenspan JS, Wolfson MR, Rubenstein SD, Shaffer TH 1990 Liquid ventilation of human preterm neonates. J Pediatr 117:106-111

6. Haidt SJ, Clark LC, Ginsbeery J 1982 Liquid perfluorocarbon replacement of eye tissue. Invest Ophthalmol 22:233

7. Hirschl RB, Conrad S, Kaiser R, Zwischenberger JB, Bartlett RH, Booth F, Cardenas V, Adult PLV Study Group 1998 Partial liquid ventilation in adult patients with ARDS: a multicenter phase I-II trial. Ann Surg 228:692-700

8. Hirschl RB, Pranikoff T, Gauger P, Schreiner RJ, Decert R, Bartlett RH 1995 Liquid ventilation in adults, children and neonates. Lancet 346:1201-1202

9. Hirschl RB, Tooley R, Parent A, Johnson K, Barlett RH 1996 Evaluation of gas exchange, pulmonary compliance, and lung injury during total and partial liquid ventilation in acute respiratory distress syndrome. Crit Care Med 24:1001-1008

10. Hirschl RB, Tooley R, Parent A, Johnson K, Barlett RH 1995 Improvement of gas exchange, pulmonary function, and lung injury with partial liquid ventilation: a study model in a setting of severe respiratory failure. Chest 108:500-508

11. Leach CL, Greenspan JS, Rubenstein SD, Shaffer TH, Wolfson MR, Jackson JC, DeLemos R, Fuhrman BP, The LiquiVent Study Group 1996 Partial liquid ventilation with perflubron in premature infants with severe respiratory distress syndrome. N Engl J Med 335:761-767

12. Al-Rahmani A, Awad K, Miller TF, Wolfson MR, Shaffer TH 2000 Effects of partial liquid ventilation with perfluorodecalin in the juvenile rabbit lung after saline injury. Crit Care Med 28:1459-1464

13. Fuhrman BP, Paczan PR, DeFrancisis M 1991 Perfluorocarbon-associated gas exchange. Crit Care Med 19:712-722

14. Loer SA, Tarnow J 1998 Effects of partial liquid ventilation with perfluorocarbons on pressure-flow relationships, vascular compliance, and filtration coefficients of isolated blood-perfused rabbit lungs. Crit Care Med 26:2037-2041

15. Merz U, Kellinghaus M, Hausler M, Pakrawan N, Klosterhalfen B, Hornchen H 2000 Partial liquid ventilation with surfactant: effects on gas exchange and lung pathology in surfactant-depleted piglets. Intensive Care Med 26:109-116

16. Nakamura T, Matsuzawa S, Sugiura M, Tamura M 2000 A randomized control study of partial liquid ventilation after airway lavage with exogenous surfactant in a meconium aspiration syndrome animal model. Arch Dis Child Fetal Neonatal Ed 82:F160-F162

17. Nakamura T, Matsuzawa M, Sugiura M, Tamura M 2000 A randomised control study of partial liquid ventilation after airway lavage with exogenous surfactant in a meconium aspiration syndrome animal mode. Arch Dis Child 82:F160-F162

18. Zobel G, Urlesberger B, Dacar D, Rödl S, Reiterer F, Friehs I 1997 Partial liquid ventilation combined with inhaled nitric oxide in acute respiratory failure with pulmonary hypertension in piglets. Pediatr Res 41:172-177

19. Miller TF, Milestone B, Stern R, Shaffer TH, Wolfson MR 2001 Effects of perfluorochemical distribution and elimination dynamics on cardiopulmonary function. J Appl Physiol 90:839-849

20. Jeng MJ, Oliver R, Wolfson MR, Shaffer TH 2002 Partial liquid ventilation: effect of initial dose and redosing strategy in acute lung injury. Pediatr Crit Care Med 3:163-170

21. Jeng MJ, Kou YR, Sheu CC, Hwang B 2002 Effects of partial liquid ventilation with FC-77 on acute lung injury in newborn piglets. Pediatr Pulmonol 33:12-21

22. Jeng MJ, Trevisanuto D, Weis CM, Fox WW, Cullen AB, Wolfson MR, Shaffer TH 2001 Role of ventilation strategy on perfluorochemical evaporation from the lungs. J Appl Physiol 90:1365-1372

23. Mazzoni M, Nugent L, Klein D, Hoffman J, Sekins KM, Flaim SF 1999 Dose monitoring in partial liquid ventilation by infrared measurement of expired perfluorochemicals. Biomed Instrum Technol 33:356-364

24. Shaffer TH, Foust R, Wolfson MR, Miller TF 1997 Analysis of perfluorochemical elimination from the respiratory system. J Appl Physiol 83:1033-1040

25. Tütüncü AS, Faithfull NS, Lachmann B 1993 Comparison of ventilatory support with intratracheal perfluorocarbon administration and conventional mechanical ventilation in animals with acute respiratory failure. Am Rev Respir Dis 148:785-792 
26. Wolfson MR, Greenspan JS, Deoras KS, Rubenstein SD, Shaffer TH 1992 Comparison of gas and liquid ventilation: clinical, physiological, and histological correlates. J Appl Physiol 72:1024-1031

27. Davidson A, Heckman JL, Donner RM, Miller TF, Shaffer TH, Wolfson MR 1998 Cardiopulmonary interaction during partial liquid ventilation in surfactant-treated preterm lambs. Eur J Pediatr 157:138-145

28. Boynton BR, Carlo WA, Jobe AH 1994 New therapies for neonatal respiratory failure. Cambridge University Press, New York, p 185

29. Notter RH, Egan EA, Kwong MS, Holm BA, Shapiro DL 1985 Lung surfactant replacement in premature lambs with extracted lipid from bovine lung lavage: effect of dose, dispersion technique, and gestational age. Pediatr Res 19:569-577

30. Wolfson MR, Kechner NE, Roache RF, Dechadarevian JP, Friss HE, Rubenstein SD, Shaffer TH 1998 Perflurocheminal rescue after surfactant treatment: effect of perflubron dose and ventilatory frequency. J Appl Physiol 84:624-640

31. Wolfson MR, Shaffer TH 1990 Liquid ventilation during early development: theory, physiologic processes and application. J Dev Physiol 13:1-12

32. Cullen AB, Cox CA, Hipp SJ, Wolfson MR, Shaffer TH 1999 Intratracheal delivery strategy of gentamicin with partial liquid ventilation. Respir Med 93:770-778

33. Wolfson MR, Greenspan JS, Shaffer TH 1996 Pulmonary administration of vasoactive substances by perfluorochemical ventilation. Pediatrics 97:449-55

34. Wolfson MR, Stern RG, Kechner N, Sekins KM, Shaffer TH 1994 Utility of a perfluorochemical liquid for pulmonary diagnostic imaging. Artif Cells Blood Substit Immobil Biotechnol 22:1409-1420
35. Biro GP, Blais P 1987 Perfluorocarbon blood substitutes. CRC Crit Rev Oncol Hematol 6:311-374

36. Reiss JC 1984 Reassessment of criteria for the selection of perfluorochemicals for second generation blood substitutes: analysis of structure/property relationships. Artif Organs 8:44-56

37. Hirschel RB, Croce M, Gore D, Wiedemann H, Davis K, Zwischenberger J, Bartlett RH 2002 Prospective, randomized, controlled pilot study of partial liquid ventilation in adult acute respiratory distress syndrome. Am J Respir Crit Care Med 165:781-787

38. Lim CM, Koh Y, Jung BO, Lee SD, Kim WS, Kim DS, Kim WD 2000 An optimal dose of perfluorocarbon for respiratory mechanics in partial liquid ventilation for dependent lung-dominant acute lung injury. Chest 117:199-204

39. Miller TF, Milestone BN, Stern RG, Shaffer TH, Wolfson MR 1999 Effect of single versus multiple dosing on perfluorochemical distribution and elimination profile during partial liquid ventilation. Pediatr Pulmonol 27:410-418

40. Tütüncü AS, Faithfull NS, Lachmann B 1993 Intratracheal perfluorocarbon administration combined with mechanical ventilation in experimental respiratory distress syndrome: dose-dependent improvement of gas exchange. Crit Care Med 21:962-969

41. Philips CM, Weis C, Fox WW, Wolfson MR, Shaffer TH 1999 On-line techniques for perfluorochemical vapor sampling and measurement. Biomed Instrum Technol 33:348-355

42. Weis C, Fox WW, Philips CM, Wolfson MR, Shaffer TH 2000 Perfluorochemical elimination from the lungs: effect of initial dose Pediatr Pulmonol 30:3244-329 